\title{
PREVALENCE AND ANTIBIOTIC SUSCEPTIBILITY PATTERN OF METHICILLIN-RESISTANT STAPHYLOCOCCUS AUREUS (MRSA) ISOLATES FROM DIFFERENT CLINICAL SPECIMENS IN A TERTIARY CARE HOSPITAL IN IMPHAL
}

\author{
Smeeta Huidrom ${ }^{1}$, Urvashi Chongtham², Biswabati Yumlembam³ ${ }^{3}$, Huidrom Lokhendro Singh 4 \\ ${ }_{1}^{1}$ Tutor, Department of Microbiology, Jawaharlal Nehru Institute of Medical Sciences, Imphal. \\ ${ }^{2}$ Associate Professor, Department of Microbiology, Jawaharlal Nehru Institute of Medical Sciences, Imphal. \\ ${ }^{3}$ Postgraduate Student, Department of Microbiology, Jawaharlal Nehru Institute of Medical Sciences, Imphal. \\ ${ }^{4}$ Professor and HOD, Department of Microbiology, Jawaharlal Nehru Institute of Medical Sciences, Imphal.
}

\begin{abstract}
BACKGROUND

The prevalence of Methicillin-resistant Staphylococcus aureus (MRSA) is increasing worldwide and is a growing public health concern. Serious infections due to Staphylococcus aureus and especially due to Methicillin-resistant Staphylococcus aureus has become a major clinical challenge.

The present study was planned to determine the prevalence of Methicillin-resistant Staphylococcus aureus (MRSA) from clinical specimens and to determine their antibiotic susceptibility pattern.
\end{abstract}

\section{MATERIALS AND METHODS}

The study was carried out in the Department of Microbiology, JNIMS, Manipur, from the year 2016 to 2017 . A total of 770 Staphylococcus aureus strains were isolated from clinical specimens like urine, pus, blood, sputum, etc. All strains were identified by standard microbiological techniques. S. aureus strains were subsequently tested for Methicillin resistance by using Cefoxitin discs. The antibiotic susceptibility pattern of all the MRSA strains identified was determined by Kirby-Bauer disc diffusion method.

\section{RESULTS}

A total number of 770 S. aureus was isolated, of which 560 were MRSA. The prevalence of MRSA was different among various clinical specimens with maximum seen in urinary isolates (88.4\%) followed by pus (79.6\%). All the 560 MRSA strains were found to be resistant to Penicillin (100\%); 76.9\% to Gentamicin, 73.5\% to Amikacin, $74.1 \%$ to Erythromycin, $69.2 \%$ to Cotrimoxazole, $77.7 \%$ to Ciprofloxacin and $60.9 \%$ to Tetracycline. MRSA strains were resistant to $\geq 8.0$ drugs, multidrug resistance. Sensitivity to Linezolid and Vancomycin was seen. A few (3/560) Vancomycin intermediate Staphylococcus aureus (VISA) strains were identified by E-test.

\section{CONCLUSION}

High rate of prevalence of MRSA with multidrug resistance of MRSA towards commonly used antibiotics was observed. Linezolid was the only antibiotic found to give uniform sensitivity (100\%). A few VISA strains were identified. The findings highlight the importance of in vitro susceptibility testing of every isolate of MRSA in clinical laboratories.

\section{KEYWORDS}

Staphylococcus aureus, Methicillin, Resistance, Vancomycin.

HOW TO CITE THIS ARTICLE: Huidrom S, Chongtham U, Yumlembam B, et al. Prevalence and antibiotic susceptibility pattern of methicillin-resistant staphylococcus aureus (MRSA) isolates from different clinical specimens in a tertiary care hospital in Imphal. J. Evolution Med. Dent. Sci. 2017;6(53):4039-4041, DOI: 10.14260/Jemds/2017/873

\section{BACKGROUND}

Staphylococcus aureus bacteria like all forms of bacteria are constantly mutating. In order to survive, bacteria evolve producing newer and stronger strains. Although antibiotics are necessary to fight bacterial infections, exposure to the drugs encourages the development of antibiotic-resistant bacteria. Subsequent to the introduction of Penicillin in clinical settings, Staphylococcus aureus strains resistant to beta-lactams including Methicillin, Methicillin-resistant

Financial or Other, Competing Interest: None.

Submission 23-05-2017, Peer Review 22-06-2017,

Acceptance 27-06-2017, Published 03-07-2017.

Corresponding Author:

Dr. Smeeta Huidrom,

Department of Microbiology,

Jawaharlal Nehru Institute of Medical Sciences,

Porompat, Imphal East,

Manipur - 795005.

E-mail: smeeta2210@gmail.com

DOI: $10.14260 /$ jemds $/ 2017 / 873$
Staphylococcus aureus (MRSA) came to be recognised as early as 1961 in the UK. ${ }^{1}$ These were seen to be resistant to fifteen to thirty different antibiotics, making the availability of effective antibiotics difficult. Making matters worse, MRSA like all forms of bacteria is constantly changing. As a result, new strains of MRSA keep appearing that are resistant to even more antibiotics. The control of the spread of MRSA is important keeping in view the implications of mortality and morbidity. Apart from an understanding of the organism's epidemiology, the knowledge of prevalence and the antibiotic pattern of MRSA help the treating physicians in determining the first line of treatment in the hospitals and thus in the effective control of spread. ${ }^{2}$ The present study was planned with an aim to determine the prevalence of MRSA from different clinical specimens viz. urine, pus, blood, sputum/throat swabs, miscellaneous (ear swabs, body fluids etc.), and to know the current status of response of MRSA to commonly used antibiotics. 


\section{MATERIALS AND METHODS}

The study was carried out in the Department of Microbiology, JNIMS, Porompat, Imphal East, during the period from January 2015 to August 2016. A total of 770 S. aureus strains were isolated from clinical specimens like urine, pus, blood, sputum, etc. All the strains were identified by colony morphology, Gram stain, Catalase and Coagulase tests and fermentation of Mannitol by conventional methods. The antimicrobial susceptibility pattern of all the recognised strains was determined by Kirby-Bauer Disc Diffusion method on Mueller-Hinton Agar using Clinical and Laboratory Standards Institute (CLSI) guidelines and included Penicillin, Erythromycin $(15 \mu \mathrm{g})$, Amikacin $(30 \mu \mathrm{g})$, Gentamicin $(10 \mu \mathrm{g})$, Cotrimoxazole $(25 \mu \mathrm{g})$, Ciprofloxacin (5 $\mu \mathrm{g})$, Tetracycline $(30 \mu \mathrm{g})$, Linezolid $(30 \mu \mathrm{g})$ and Teicoplanin $(30 \mu \mathrm{g})$. Discs from HiMedia were used and the turbidity of the suspension was adjusted to $0.5 \mathrm{McF}$ arland standard. $S$. aureus ATCC 25923 was used as quality control for disc diffusion. S. aureus strains were then tested for Methicillin resistance using Cefoxitin $(30 \mu \mathrm{g})$.

\section{RESULTS}

During the study period, 7200 clinical specimens were received; 770 isolates of $S$. aureus were identified, of which 560 were MRSA [Table 1].

\begin{tabular}{|c|c|c|c|}
\hline $\begin{array}{c}\text { Clinical } \\
\text { Specimen }\end{array}$ & S. aureus & MRSA (n) & \begin{tabular}{|c|} 
Percentage MRSA \\
of $S$. aureus Isolates
\end{tabular} \\
\hline Urine & 226 & 200 & 88.4 \\
\hline Pus & 118 & 94 & 79.6 \\
\hline Blood & 310 & 192 & 61.9 \\
\hline Sputum & 44 & 32 & 72.7 \\
\hline Throat swab & 40 & 26 & 65 \\
\hline Body fluids & 18 & 10 & 55.5 \\
\hline Ear swabs & 14 & 6 & 42.8 \\
\hline Total & 770 & 560 & 72.7 \\
\hline
\end{tabular}

The antimicrobial susceptibility pattern was found to vary across all samples with maximum observed in urine isolates 200/226 (88.4\%).

The antimicrobial susceptibility pattern of the MRSA isolates showed maximum resistance to Penicillin (100\%), while all $(100 \%)$ MRSA isolates were sensitive to Linezolid [Table 2].

\begin{tabular}{|c|c|c|}
\hline Antibiotic & Resistant; n (\%) & Sensitive; n (\%) \\
\hline Penicillin $(10 \mathrm{units})$ & $560(100)$ & $0(0)$ \\
\hline Amikacin $(30 \mu \mathrm{g})$ & $412(73.5)$ & $148(26.5)$ \\
\hline Ciprofloxacin $(5 \mu \mathrm{g})$ & $125(22.3)$ & $435(77.7)$ \\
\hline Gentamicin $(50 \mu \mathrm{g})$ & $431(76.9)$ & $129(23.1)$ \\
\hline Cotrimoxazole $(25 \mu \mathrm{g})$ & $388(69.2)$ & $172(30.8)$ \\
\hline Linezolid $(30 \mu \mathrm{g})$ & $0(0)$ & $100(100)$ \\
\hline Erythromycin $(15 \mu \mathrm{g})$ & $415(74.1)$ & $145(25.9)$ \\
\hline Teicoplanin $(30 \mu \mathrm{g})$ & $113(20.1)$ & $447(79.9)$ \\
\hline Tetracycline $(30 \mu \mathrm{g})$ & $219(39.1)$ & $341(60.9)$ \\
\hline Vancomycin $(30 \mu \mathrm{g})$ & $3^{*}(0.5)$ & $557(99.5)$ \\
\hline Nitrof & $50 / 226(22.1)$ & $176 / 226(77.9)$ \\
\hline
\end{tabular}

\begin{tabular}{|l|l|l|}
\hline Nitrofurantoin $\dagger(30 \mu \mathrm{g})$ & $50 / 226(22.1)$ & $176 / 226(77.9)$ \\
\hline
\end{tabular} Table 2. Antibiotics Susceptibility Pattern of MRSA Isolates

*Vancomycin Intermediate S. aureus (VISA) by E-test tonly for urine isolates.

\section{DISCUSSION}

MRSA has been observed to be one of the major nosocomial agents causing significant morbidity and mortality. Infected patients are important reservoirs of MRSA in Hospitals/Institutions. Healthcare workers by transient hand carriage are a predominant mode of patient to patient transmission. ${ }^{1}$

Unlike the Western world, the significance of MRSA came to be recognised late in India and emerged as a problem only in the 80 s and 90s. ${ }^{3}$ The present study identifies and analyses the prevalence and antimicrobial susceptibility pattern of MRSA isolates obtained from different clinical specimens in a specific geographical setting.

Out of 7200 clinical specimens, 770 were identified as $S$. aureus. Out of these 770 isolates, 560 (72.7\%) were found to be MRSA, which compares well with the prevalence of MRSA in other parts of India (30 - 80\%) in various studies. ${ }^{4}$ Kulkarni et al reported a similar prevalence rate of $70.33 \%$, while D. Majumdar et al reported 52.9\% among patients and carriers in their study in Assam. ${ }^{1,5}$ Prevalence rates as low as $6.9 \%$ have also been reported by Chakravarthy et $\mathrm{al}^{6}$ and $31 \%$ by Rajaduraipandi $\mathrm{K}$ et al.,3

In the present study, highest percentage of MRSA strains were seen in urine isolates (88.4\%) followed by pus (79.6\%); $13.2 \%$ MRSA were isolated from miscellaneous samples like throat swab, ear swab, sputum and body fluids. Similar observations were found by Kulkarni et $\mathrm{al}^{1}$ and Anupurba et al $^{6}$ who reported $82.38 \%$ and $76 \%$ MRSA from urine and $64.67 \%$ and $52.5 \%$ from pus respectively. ${ }^{1,7}$ Higher figures have however been reported by Bandaru et $\mathrm{al}^{8}$ and Mehta et $\mathrm{al}^{9}$ from pus samples, $67.28 \%$ and $74.28 \%$ respectively. 8,9 Rajaduraipandi et al observed a higher percentage from sputum/throat swabs (35.7\%). ${ }^{3}$

The drug resistance patterns of MRSA, isolated from different samples were seen to be variable. All the 560 MRSA strains were found to be resistant to Penicillin (100\%), Gentamicin (76.9\%), Amikacin (73.5\%), Erythromycin (74.1\%) and Cotrimoxazole (69.2\%). Ciprofloxacin and Tetracycline showed a sensitivity of $77.7 \%$ and $60.9 \%$, respectively. Good response was also seen against Teicoplanin $(79.9 \%)$. All the MRSA strains were sensitive to Linezolid (100\%).

The high resistance rate against Gentamicin and Amikacin observed in our study is similar to those of Rajaduraipandi et $\mathrm{al}^{3}$ (63.6\%), Majumdar et $\mathrm{al}^{5}$ (94\%), Bandaru et $\mathrm{al}^{8}$ (85.80\%) and Kulkarni et $\mathrm{al}^{1}(52.57 \%)$. However, Pulimood et $\mathrm{al}^{10}$ observed a low resistance rate of $8 \%$.

Gentamicin resistance has been reported worldwide and has been attributed to drug inactivation by cellular transferase enzyme. ${ }^{8}$

In our study, MRSA strains showed a high resistance to Erythromycin $(73.7 \%)$ and are similar to the findings of Bandaru et $\mathrm{al}^{8}$ (95.67\%) and Mukesh Pal et $\mathrm{al}^{4}$ (85.71\%). Strains resistant to Erythromycin are generally cross resistant to Azithromycin and Clarithromycin. ${ }^{8}$

Various studies have also reported resistance to Ciprofloxacin ranging from $12.8 \%$ to $98.9 \%$. Rajaduraipandi et $\mathrm{al}^{3}$ reported $12.8 \%$, Pulimood et al $1090 \%$ and $88 \%$ by Bandaru et al. ${ }^{8}$ Our present study showed $22.4 \%$ resistance rate. 
The present study shows good sensitivity rate against Linezolid, Teicoplanin and Vancomycin. Linezolid showed good activity against all Staphylococci including strains resistant to Methicillin. It is thus a promising therapeutic option.

A very high prevalence rate of MRSA was observed in the present study (72.7\%). Maximum of the MRSA strains were found to be resistant to $\geq 8$ antibiotics, and hence were multidrug resistant MDR (MRSA). Even though Vancomycin is the drug of choice for MDR (MRSA), it is considered inferior to beta-lactams for the treatment of MSSA bacteraemia and endocarditis. The first generation Cephalosporins are the drug of choice for treatment of MSSA infections in patients who cannot tolerate anti-Staphylococcal Penicillins.

210 strains $(27.3 \%)$ in the present study were found to be sensitive to Methicillin (MSSA). They were also seen to be sensitive to most of the antibiotics. Similar observation has been reported by Arora et al. ${ }^{11}$ It is thus imperative to encourage the de-escalation of the use of Vancomycin to betaLactams in all cases of MSSA. MRSA isolates being rampant, it is important that treating physicians de-escalate to betaLactams once culture results reveal an MSSA isolate, so as to preserve glycopeptides and Linezolid for use against MRSA.

MIC determination for Vancomycin was done using E-test strips (Bio-Merieux India Pvt. Ltd.) according to manufacturer's instructions. Of the 560 isolates, 557 were found to be sensitive with MIC $\leq 2 \mathrm{mg} / \mathrm{L}$. However, 3 strains were found with MIC of $4 \mathrm{mg} / \mathrm{L}$, and could be identified as Vancomycin Intermediate $S$. aureus (VISA). They were all however sensitive to Linezolid. No Vancomycin resistant $S$. aureus (VRSA) was found by the E-test.

Our study was however limited by the non-inclusion of carriers, which would have helped us to correlate with the high rate of MRSA. Newer drugs like Daptomycin and $4^{\text {th }}$ generation Cephalosporins like Ceftaroline and Tigecycline could have been included to assess their activity against MRSA. Molecular studies could not be done.

\section{CONCLUSION}

Our study showed a very high incidence of MRSA in our Hospital. A regular surveillance of Hospital-associated infections including monitoring and strict anti-microbial stewardship and control measures to reduce the high incidence of MRSA infections to prevent the spread of such strains needs to be implemented.

MRSA isolates were more Multidrug Resistant (MDR) as compared to the MSSA isolates. Glycopeptides and Linezolid remains the mainstay for treatment of such MDR-MRSA.

In conclusion, our study has highlighted the high prevalence of MRSA and the emergence of $S$. aureus with intermediate resistance to Vancomycin. There is thus a need to enforce the judicious use of Vancomycin. Alternative antiMRSA drugs should be used when appropriate in order to balance the antibiotic pressure of Vancomycin on the bacterial population.
One needs to keep in mind that the use of newer antibacterial drugs needs to be carefully defined to prevent misuse and subsequent resistance to these drugs.

\section{REFERENCES}

[1] Kulkarni S, Khare A, Kaur DC. Prevalence of methicillin resistant staphylococcus aureus- a study in a tertiary care rural hospital. Indian J of Basic and Appl Med Res 2014;3(3):414-21.

[2] Mehndiratta PL, Bhalla P. Typing of methicillin resistant staphylococcus aureus: a technical review. Indian J Med Microbiol 2012;30(1):16-23.

[3] Rajaduraipandi K, Mani KR, Selarm KP, et al. Prevalence and antimicrobial susceptibility pattern of methicillin resistant staphylococcus aureus: a multicentre study. IJMM 2006;24(1):34-8.

[4] Singh MP, Sharma SK, Shukla S, et al. Prevalence rate and antibiotic susceptibility test (AST) pattern of methicillin resistant staphylococcus aureus (MRSA) isolates from different clinical specimens of teerthankar mahaveer hospital, Moradabad, India. Int J Curr Microbiol App Sci 2013;2(11):307-14.

[5] Majumder D, Bordoloi JNS, Phukan AC, et al. Antimicrobial susceptibility pattern among methicillin resistant staphylococcus isolates in Assam. IJMM 2001;19(3):138-40.

[6] Chakravarthy A, Talwar V, Gupta H. Antibiotic resistant pattern of staphylococcus aureus with special reference to methicillin resistant strains, Indian. Journal of Medical Research 1998;87:576-9.

[7] Anupurba S, Sen MR, Nath G, et al. Prevalence of methicillin resistant staphylococcus aureus in a tertiary care referral hospital in Eastern Uttar Pradesh. IJMM 2003;21(1):49-51.

[8] Bandaru NR, Prabhakar T. Prevalence and antimicrobial susceptibility pattern of methicillin resistant staphylococcus aureus (MRSA) in and around Visakhapatnam, Andhra Pradesh, India. JPBMS 2011;4(03):1-5.

[9] Mathur M, Taklikar S, Sarkar S, et al. A four year audit of MRSA in a tertiary care hospital. Bombay Hospital Journal 2007;49(4):579-83.

[10] Pulimood TB, Lalitha MK, Jesudason MV, et al. The spectrum of antimicrobial resistance among methicillin resistant staphylococcus aureus (MRSA) in a tertiary care in India. Indian J Med Res 1996;103:212-5.

[11] Gupta N, Aparna, Saini S, et al. In vitro activity of linezolid in staphylococcus aureus. I JMM 2003;21(4):289-90. 